\title{
Pharmacokinetics of bevacizumab after topical and intravitreal administration in human eyes
}

\author{
Elad Moisseiev • Michael Waisbourd • Elad Ben-Artsi • \\ Eliya Levinger • Adiel Barak • Tad Daniels • Karl Csaky • \\ Anat Loewenstein • Irina S. Barequet
}

Received: 20 June 2013 /Revised: 26 September 2013 / Accepted: 1 October 2013 /Published online: 31 October 2013

(C) The Author(s) 2013. This article is published with open access at Springerlink.com

\begin{abstract}
Background Topical bevacizumab is a potential treatment modality for corneal neovascularization, and several recent studies have demonstrated its efficacy. No previous study of the pharmacokinetics of topical bevacizumab has been performed in human eyes. The purpose of this study is to investigate the pharmacokinetics of topical administration of bevacizumab in human eyes, and also to compare the pharmacokinetics of intravitreal bevacizumab injections with previously reported data.

Methods Twenty-two (22 eyes) were included in this study, and divided into four groups: eight patients received topical bevacizumab and aqueous samples were obtained 1 hour later during cataract extraction surgery (group 1), eight patients received topical bevacizumab and vitreous samples were obtained 1 day later during pars-plana vitrectomy (PPV) (group 2), three patients received intravitreal bevacizumab and vitreous samples were obtained during PPV (group 3). Vitreous samples from three patients who received no bevacizumab served as controls (group 4). All samples underwent enzyme-linked immunosorbent assay to detect bevacizumab.
\end{abstract}

Elad Moisseiev and Michael Waisbourd: equal contribution

E. Moisseiev $(\bowtie) \cdot$ M. Waisbourd · E. Levinger · A. Barak • A. Loewenstein

Department of Ophthalmology, Tel-Aviv Sourasky Medical Center, Affiliated to the Sackler School of Medicine, Tel Aviv University, Tel Aviv, 6 Weizman Street, Tel-Aviv 64239, Israel

e-mail: elad_moi@netvision.net.il

E. Ben-Artsi • I. S. Barequet

Department of Ophthalmology, Sheba Medical Center, Affiliated to the Sackler School of Medicine, Tel Aviv University, Tel Aviv, Israel

T. Daniels $\cdot$ K. Csaky

Retina Foundation of the Southwest, Dallas, TX, USA
Results No bevacizumab was detected in the aqueous or vitreous of any topically treated eyes. The mean vitreal halflife for intravitreally injected bevacizumab was 4.9 days in four non-vitrectomized eyes and 0.66 days in one previously vitrectomized eye.

Conclusions Topically administered bevacizumab does not penetrate the cornea into the anterior chamber and vitreous cavity, indicating that topical use for treating corneal neovascularization has minimal risk of intraocular penetration and adverse events related to intraocular vascular endothelial growth factor inhibition. The half-life following intravitreal bevacizumab injection measured in this study is comparable to that of previous reports, and includes the first demonstration of a significantly reduced half-life following intravitreal injection in a previously vitrectomized eye.

Keywords Bevacizumab · Topical · Intravitreal · Pharmacokinetics $\cdot$ Half-life

\section{Introduction}

Bevacizumab (Avastin ${ }^{\circledR}$, Genentech, San Francisco, CA, USA) is a recombinant humanized monoclonal immunoglobulin antibody specifically directed against human vascular endothelial growth factor (VEGF). It is currently the most widely used anti-VEGF agent in ophthalmology $[1,2]$. Bevacizumab is administered intravitreally, most commonly for the treatment of neovascular age-related macular degeneration (AMD), diabetic retinopathy, and retinal vein occlusions [3]. Several studies have demonstrated the efficacy of topical bevacizumab administration for the treatment of corneal neovascularization (NV) in both experimental animal models [4-7] and human patients [8-10].

There are only a few pharmacokinetic studies on topical bevacizumab, and they were performed solely in experimental 
animal models. Nomoto et al. [11] reported minimal aqueous concentration $(0.6 \pm 0.6 \mathrm{ng} / \mathrm{ml})$ after 1 week of topical administration of $25 \mathrm{mg} / \mathrm{ml}$ bevacizumab 6 times daily in rabbit eyes. Yoeruek et al. [12] applied bevacizumab $25 \mathrm{mg} /$ $\mathrm{ml}$ drops every minute for 30 minutes to rabbit corneas, and the aqueous penetration after this mega-dose of bevacizumab was minimal, as demonstrated by the fact that the detected amount of bevacizumab was lower by a factor of over 1,000 compared with the initial dose. Dastjerdi et al. [13] reported minimal penetration of topical bevacizumab in normal mice corneas. Others have shown that corneal penetration of bevacizumab was greater in mice with corneal NV and in those with denuded corneal epithelium, and that it can be detected in the aqueous, vitreous, serum, and even in the contralateral eye following subconjunctival injection in several animal models [11, 13, 14]. Kim et al. [14] postulated that intraocular penetration of bevacizumab after subconjunctival injection occurs through the sclera and systemic circulation.

The purpose of this study was to conduct what, to the best of our knowledge, is the first evaluation of the pharmacokinetics of topical bevacizumab in human eyes. We also compared our findings on the pharmacokinetics of intravitreal bevacizumab injection to previously reported data.

\section{Methods}

Study subjects

The study protocol followed the tenets of the Declaration of Helsinki, and was approved by the Institutional Review Board of the Tel Aviv Medical Center. All patients agreed to participate after a thorough explanation of the nature of the study, and gave their written informed consent to participate prior to study entry. This prospective study was conducted at the Department of Ophthalmology of the Tel Aviv Medical Center. All patients volunteered to participate in it, and were recruited from among patients scheduled for elective surgery at our department. They were divided into three groups according to bevacizumab treatment protocol and their subsequent surgery (Table 1): topical bevacizumab and subsequent cataract extraction (group 1), topical bevacizumab and subsequent pars plana vitrectomy (PPV) (group 2), and intravitreal bevacizumab and subsequent PPV (group 3). Control samples were obtained from three additional patients who underwent PPV and had never received any previous treatment with bevacizumab (group 4).

All 22 patients were 18 years or older, and none had corneal neovascularization or epithelial defects prior to PPV or cataract surgery. Only one eye of each patient was included for analysis. The demographic and clinical data that were recorded included age, gender, previous ocular history, previous administration of bevacizumab of any kind, indication for surgery, time between administration of bevacizumab and sampling, and details of the surgery.

\section{Bevacizumab administration}

The study participants were divided into four groups. The group 1 patients were treated with topical bevacizumab $25 \mathrm{mg} / \mathrm{ml}$ : they received a total of four drops, with 10 minute intervals between drops, 1 hour prior to cataract extraction surgery. The group 2 patients received four drops of topical bevacizumab $25 \mathrm{mg} / \mathrm{ml}$ on the day before PPV surgery (once every 6 hours), and an additional four drops 1 hour prior to undergoing surgery at 10-minute intervals. Two patients in group 2 had been treated with intravitreal bevacizumab prior to their inclusion in this study. All group 1 and 2 patients were instructed to perform punctal occlusion for at least 60 seconds after instillation of the bevacizumab drops. The group 3 patients received an intravitreal injection of bevacizumab $1.25 \mathrm{mg} / 0.05 \mathrm{ml}$ prior to undergoing PPV: the administration of bevacizumab was indicated as part of their treatment, since they all underwent PPV for the removal of vitreous hemorrhage $(\mathrm{VH})$ secondary to proliferative diabetic retinopathy (PDR). The time between bevacizumab injection and vitreous sampling differed between patients in group 3 .

The topical and intravitreal bevacizumab administered in this study were prepared under sterile conditions in the pharmacy at our institution. Topical bevacizumab was administered from bottles containing 12 drops of
Table 1 Bevacizumab treatment protocols, surgery type and sampling site for each study group

\begin{tabular}{|c|c|c|c|c|}
\hline Group & $\mathrm{n}$ & Treatment protocol & Surgery & Sampling site \\
\hline 1 & 8 & $\begin{array}{l}\text { Topical - four drops of bevacizumab } 25 \mathrm{mg} / \mathrm{ml} \text {, } \\
\text { one drop every } 10 \text { minutes } 1 \text { hour prior to surgery }\end{array}$ & Cataract extraction & Aqueous \\
\hline 2 & 8 & $\begin{array}{l}\text { Topical - four drops of bevacizumab } 25 \mathrm{mg} / \mathrm{ml} \text {, } \\
\text { one drop every } 6 \text { hours } 1 \text { day before surgery, } \\
\text { and another four drops, one every } 10 \text { minutes } \\
1 \text { hour prior to surgery }\end{array}$ & Pars plana vitrectomy & Vitreous \\
\hline 3 & 3 & $\begin{array}{l}\text { Intravitreal - injection of bevacizumab } \\
1.25 \mathrm{mg} / 0.05 \mathrm{ml}\end{array}$ & Pars plana vitrectomy & Vitreous \\
\hline 4 & 3 & None & Pars plana vitrectomy & Vitreous \\
\hline
\end{tabular}

- Serum samples were also obtained at the time of surgery in two patients from group 2 and one from group 3. 
bevacizumab $25 \mathrm{mg} / \mathrm{ml}$. Syringes containing bevacizumab $1.25 \mathrm{mg} / 0.05 \mathrm{ml}$ were used for intravitreal administration. Both preparations were refrigerated at $4{ }^{\circ} \mathrm{C}$ for no longer than 5 days prior to use.

\section{Surgical procedures and sampling}

Cataract extraction surgery was performed by phacoemulsification using the Infinity Vision System (Alcon Laboratories Inc., Fort Worth, TX, USA). All PPVs were 23gauge, performed using the 23-gauge Constellation Vision System (Alcon Laboratories Inc., Fort Worth, TX, USA). No intraoperative or postoperative complications were encountered. Undiluted aqueous samples were drawn from the group 1 eyes through a paracentesis using a cannula prior to irrigation, while undiluted vitreous samples were drawn through a sclerotomy using the vitrector prior to irrigation in the eyes of the other three groups. Blood samples were also drawn at the time of surgery from three patients in group 2 .

\section{Enzyme-linked immunosorbent assay for bevacizumab}

Samples obtained from groups 1-4 underwent enzyme-linked immunosorbent assay (ELISA) for bevacizumab. All steps of the ELISA process were performed at room temperature. Nunc 96-well Maxisorp plates (Thermo Scientific, Rockford, IL, USA) were coated with $100 \mathrm{ul} /$ well of hrVEGF (Prospec, East Brunswick, NJ) at $2 \mathrm{ng} / \mathrm{ul}$ overnight, followed by blocking at $0.5 \%$ BSA in PBS for 1 hour. Aqueous samples were diluted 1:4, and vitreous and serum samples were diluted $1: 2$ in $1 \%$ BSA in PBS with $0.05 \%$ Tween 20, and incubated for 2 hours. The wells were then washed with $0.05 \%$ Tween 20 in PBS and incubated for $30 \mathrm{~min}$ in goat anti-human IgG conjugated to horseradish peroxidase (Jackson ImmunoResearch, West Grove, PA, USA) diluted $1: 10,000$ in $1 \%$ BSA in PBS with $0.05 \%$ Tween 20. The wells were then thoroughly washed before development with $100 \mathrm{ul} /$ well of TMB substrate (Pierce Protein Biology, Rockford, IL, USA) for up to 30 minutes in dark conditions. Absorbance was measured using optical density (OD) values obtained from a microplate reader at $450 \mathrm{~nm}$, with $620 \mathrm{~nm}$ as a reference. Bevacizumab concentrations were compared to standard curves generated with 1:2 serial dilutions from $400 \mathrm{ng} / \mathrm{ml}$ in $1 \%$ BSA in PBS with $0.05 \%$ Tween 20 with $10 \%$ human serum. This method is very sensitive, and is capable of detecting bevacizumab from a minimal concentration of $6.25 \mathrm{ng} / \mathrm{ml}$. The standard curve was generated from $6.25 \mathrm{ng} / \mathrm{ml}$ to $300 \mathrm{ng} / \mathrm{ml}$, using nonspecific human $\operatorname{IgG}$ as a negative control in place of the bevacizumab. The detectable range of bevacizumab by this method was therefore between $6.25 \mathrm{ng} / \mathrm{ml}$ and $300 \mathrm{ng} / \mathrm{ml}$. For quality control, all drawn samples were divided in two and analyzed separately. The results of both samples of each patient were then averaged.

Statistical analysis and pharmacokinetic calculations

Data were analyzed using SPSS for windows version 17. Values are presented as mean \pm standard deviation, unless otherwise specified. The bevacizumab concentration was multiplied by estimated volumes of $5.5 \mathrm{ml}$ for vitreous samples and 5,000 $\mathrm{ml}$ for serum samples in order to calculate its mass $[15,16]$. Half-life $\left(\mathrm{T}_{1 / 2}\right)$ was calculated according to first-order kinetics.

\section{Results}

A total of 22 eyes of 22 patients were included in this study. There were eight males (36.3\%) and 14 females $(73.7 \%)$, with a mean age of $69.2 \pm 10.2$ years (range 53 to 89 years). Their baseline characteristics and indications for surgery are provided in Table 2.

\section{Pharmacokinetics of topical bevacizumab}

None of the eight patients in group 1 had received any prior treatment with bevacizumab. Aqueous samples from their eyes were obtained and assayed for bevacizumab. Their OD values were $1.21 \pm 0.06$ (range 0.038 to 0.246 ), corresponding with no detectable bevacizumab. The eight patients in group 2 were also treated with topical bevacizumab, but on a longer protocol. Vitreous samples were obtained from their eyes and assayed for bevacizumab. Notably, two of these patients had each received one intravitreal injection of bevacizumab $1.25 \mathrm{mg} / 0.05 \mathrm{ml}$ prior to their enrollment into this study: patient \#11 (Table 2) received the injection 10 weeks prior to surgery, and patient \#12 received it 12 weeks prior to surgery.

The OD values in the vitreous samples from the six group 2 patients who had never been treated with bevacizumab were $0.287 \pm 0.19$ (range 0.059 to 0.636 ), corresponding with no detectable bevacizumab in any of them. An aqueous sample was available from one of these patients (patient \#14), and no bevacizumab was detected in it. Bevacizumab was, however, detected in the vitreous samples from the two patients who were previously treated intravitreally: the vitreal concentration was $92.86 \mathrm{ng} / \mathrm{ml}$ in patient $\# 11$ and $89.3 \mathrm{ng} / \mathrm{ml}$ in patient \#12.

No pharmacokinetic calculations could be performed in the aqueous or vitreous samples from patients who were only treated topically, since there was no detectable bevacizumab. The bevacizumab that was detected in the two patients in group 2 was most likely due to the previous intravitreal injections and not to the topical administration in this 
Table 2 Baseline characteristics of the study patients

\begin{tabular}{|c|c|c|c|c|c|}
\hline Patient no. & Gender & Age & Group & Surgery & $\begin{array}{l}\text { Indication } \\
\text { for surgery }\end{array}$ \\
\hline 1 & M & 70 & 1 & Phaco & Cataract \\
\hline 2 & $\mathrm{~F}$ & 89 & 1 & Phaco & Cataract \\
\hline 3 & F & 72 & 1 & Phaco & Cataract \\
\hline 4 & M & 53 & 1 & Phaco & Cataract \\
\hline 5 & F & 87 & 1 & Phaco & Cataract \\
\hline 6 & M & 56 & 1 & Phaco & Cataract \\
\hline 7 & $\mathrm{~F}$ & 78 & 1 & Phaco & Cataract \\
\hline 8 & M & 72 & 1 & Phaco & Cataract \\
\hline 9 & $\mathrm{~F}$ & 77 & 2 & PPV & ERM \\
\hline 10 & M & 72 & 2 & PPV & ERM \\
\hline 11 & M & 69 & 2 & PPV & $\mathrm{VH} \mathrm{d} / \mathrm{t}$ PDR \\
\hline 12 & $\mathrm{~F}$ & 75 & 2 & PPV & $\mathrm{VH} d / \mathrm{t}$ PDR \\
\hline 13 & $\mathrm{~F}$ & 63 & 2 & PPV & $\mathrm{VH} \mathrm{d} / \mathrm{t}$ PDR \\
\hline 14 & $\mathrm{~F}$ & 66 & 2 & PPV & FTMH \\
\hline 15 & M & 53 & 2 & PPV & ERM \\
\hline 16 & $\mathrm{~F}$ & 73 & 2 & PPV & $\mathrm{VH} \mathrm{d} / \mathrm{t}$ PDR \\
\hline 17 & M & 59 & 3 & PPV & $\mathrm{VH} \mathrm{d} / \mathrm{t}$ PDR \\
\hline 18 & $\mathrm{~F}$ & 73 & 3 & PPV & $\mathrm{VH} \mathrm{d} / \mathrm{t}$ PDR \\
\hline 19 & $\mathrm{~F}$ & 64 & 3 & PPV & $\mathrm{VH} \mathrm{d} / \mathrm{t}$ PDR \\
\hline 20 & $\mathrm{~F}$ & 82 & 4 & PPV & ERM \\
\hline 21 & F & 56 & 4 & PPV & ERM \\
\hline 22 & $\mathrm{~F}$ & 63 & 4 & PPV & FTMH \\
\hline
\end{tabular}

$\mathrm{M}=$ male $\mathrm{F}=$ female Phaco = phacoemulsification; $\mathrm{PPV}=$ pars plana vitrectomy; $\mathrm{ERM}=$ epiretinal membrane; $\mathrm{VH} d / \mathrm{t} \mathrm{PDR}=$ vitreous hemorrhage due to proliferative diabetic retinopathy; FTMH $=$ fullthickness macular hole.

study. The $\mathrm{T}_{1 / 2}$ was 5.7 days for patient $\# 11$ and 7.3 days for patient $\# 12$.

\section{Pharmacokinetics of intravitreal bevacizumab}

In group 3, patients underwent intravitreal injection of bevacizumab $1.25 \mathrm{mg} / 0.05$ prior to PPV for the removal of VH secondary due to PDR. None had been treated by intravitreal bevacizumab prior to inclusion in this study. Vitreous samples were obtained from their eyes and assayed for bevacizumab. The time between intravitreal injection and vitreal sampling varied between these three patients (Table 3 ), and bevacizumab was detected in the vitreous samples of all of them. In patient \#17, PPV had been performed 2 months after intravitreal injection, and a concentration of $19.12 \mathrm{ng} / \mathrm{ml}$ of bevacizumab was detected. In patient \#18, PPV had been performed 1 month after intravitreal injection, and a concentration of $107.27 \mathrm{ng} / \mathrm{ml}$ was detected. The $T_{1 / 2}$ was 4.1 days for patient \#17 and 2.5 days for patient \#18.

Patient \#19 was previously vitrectomized, and underwent a standard core and peripheral vitrectomy due to a non-clearing
Table 3 Intervals between intravitreal bevacizumab administration and vitreal sampling during pars plana vitrectomy and calculated $T_{1 / 2}$ values for patients who received intravitreal bevacizumab

\begin{tabular}{llll}
\hline Patient & Group & Intervals (days) & $\begin{array}{l}\text { Calculated } \\
\mathrm{T}_{1 / 2} \text { (days) }\end{array}$ \\
\hline 11 & 2 & 70 & 5.7 \\
12 & 2 & 84 & 7.3 \\
17 & 3 & 56 & 4.1 \\
18 & 3 & 28 & 2.5 \\
$19^{\mathrm{b}}$ & 3 & 7 & 0.66 \\
\hline
\end{tabular}

${ }^{\text {a }}$ Half-life $\left(\mathrm{T}_{1 / 2}\right)$ values for bevacizumab are provided.

${ }^{\mathrm{b}}$ This patient had previously undergone vitrectomy in the study eye, leading to a significantly reduced $T_{1 / 2}$ value.

VH 1 year prior to enrollment. The patient was recruited to this study before undergoing repeated PPV for recurrent VH in the same eye, and received an intravitreal injection of bevacizumab 1 week prior to surgery. A concentration of $149.37 \mathrm{ng} / \mathrm{ml}$ was detected in the vitreous sample obtained during the study PPV, corresponding with a $\mathrm{T}_{1 / 2}$ of 0.66 days.

No trace of bevacizumab was detected in any of the vitreous control samples from the three patients in group 4 .

Systemic pharmacokinetics of topical and intravitreal bevacizumab

Serum samples were available for patient \#15 and patient \#16 (group 2) who received topical bevacizumab, and no trace of bevacizumab was detected in them. A serum sample was also available for patient \#18 (group 3), who received an intravitreal bevacizumab injection 1 month prior to surgery: a sample obtained at the time of surgery contained a serum concentration of $44.85 \mathrm{ng} / \mathrm{ml}$, corresponding with a systemic $\mathrm{T}_{1 / 2}$ of 11.3 days for bevacizumab after intravitreal administration.

\section{Discussion}

Bevacizumab was not detected in any of the eyes in which it was administered topically. It was not detected in the aqueous samples of any of the eight patients in group 1, nor in the vitreous samples of the six patients in group 2 who had not been previously treated by intravitreal injection. It was also not detected in serum samples from two patients who were treated solely by topical bevacizumab. These findings are compatible with previous data from animal models, in which corneal penetration was demonstrated as being extremely low, even at higher doses and when following more prolonged treatment protocols [11-14]. An intact corneal epithelium was shown to provide an effective barrier that almost 
completely excludes molecules larger than $1 \mathrm{~nm}$ [17]. Since bevacizumab is approximately $12 \mathrm{~nm}$ long [13], its penetration through healthy corneas is unlikely. Additionally, it has been demonstrated that a monoclonal antibody is unable to penetrate porcine cornea in vitro [18]. No pharmacokinetic calculations could be performed in the current study, since no bevacizumab was detected in eyes that were treated topically. However, our results demonstrate that topical bevacizumab is associated with virtually no penetration in human eyes with intact corneas, corroborating previous findings in experimental animal models.

It should be noted that corneal penetration has been demonstrated to be significantly increased when corneal NV or epithelial defects are present [13]. Several studies suggested that topical bevacizumab may impair corneal epithelial healing and cause stromal thinning after prolonged use [7, 19, 20]. It is also possible that the TWEEN buffer that is present in the commercially available bevacizumab preparation (Avastin ${ }^{\circledR}$ ) acts as a detergent that can enhance intraocular penetration [12, 21]. Therefore, it may be assumed that its intraocular penetration will be higher in patients with corneal NV and epithelial defects treated for long periods of time with topical bevacizumab, but several studies have reported very favorable safety profiles for topical administration of bevacizumab in patients with corneal NV $[7-9,22,23]$. An in vitro study demonstrated that the median inhibitory concentration of bevacizumab is $22 \mathrm{ng} / \mathrm{ml}$, and that the minimal concentration that completely blocks all VEGFinduced endothelial cell proliferation, migration, and hyperpermeability is $500 \mathrm{ng} / \mathrm{ml}$ [24]. Even if corneal NV and associated epithelial defects increase the risk of bevacizumab penetration, it is probably unlikely to achieve levels that can result in either effective intraocular activity or adverse events. The implications of these findings are encouraging, since corneal NV is an ocular surface disease, and topical administration of bevacizumab will achieve a high local therapeutic level $[12,17]$, with minimal risk for intraocular or systemic adverse effects related to VEGF inhibition.

Two of our five patients who were treated with intravitreal injection of bevacizumab $1.25 \mathrm{mg} / 0.05 \mathrm{ml}$ had also been treated with topical bevacizumab according to the group 2 protocol, but the contribution of the latter to the detected level in the vitreous was assumed to be negligible. The time between intravitreal injection and vitreous sampling during PPV and detected concentrations are specified in the Results section and Table 3. Four of these eyes underwent PPV for the first time in this study. Clearance of bevacizumab was calculated to have a $\mathrm{T}_{1 / 2}$ that varied between 2.5 and 7.3 days, with a mean of 4.9 days. These results are compatible with previous pharmacokinetic studies of intravitreal bevacizumab injection in non-vitrectomized human eyes, in which vitreal $\mathrm{T}_{1 / 2}$ varied between 3 and 7.8 days [25-27]. They are also comparable to previous studies on animal models that reported the $T_{1 / 2}$ of vitreal bevacizumab between 4.2 and 6.6 days [28-30].

A serum sample was available for one of our patients who underwent intravitreal bevacizumab injection, and a systemic $\mathrm{T}_{1 / 2}$ of 11.3 days was calculated. This value is comparable with a previous animal study that reported a $T_{1 / 2}$ of 12.9 days [11]. Bevacizumab was not detected in serum samples from two patients who were solely treated topically, demonstrating that topical administration with punctual occlusion is associated with virtually no systemic absorption of bevacizumab.

One eye included in our study had previously been vitrectomized. The detected vitreal concentration of bevacizumab following intravitreal injection in that eye resulted in a calculated $T_{1 / 2}$ of 0.66 days. This $T_{1 / 2}$ is significantly shorter than that found in non-vitrectomized eyes, both in our study and in reports by others [25-27]. It is possible that the vitreous serves as a reservoir for injected bevacizumab, and that its absence allows more rapid clearance from the eye. The blood-brain and blood-retinal barriers express neonatal $\mathrm{Fc}$ receptor that binds to the $\mathrm{Fc}$ portion of antibodies and actively transports them into the systemic circulation [31-33]. In vitrectomized eyes, bevacizumab may more readily be transported out of the eye by this mechanism. This is consistent with previous studies that demonstrated significantly reduced $\mathrm{T}_{1 / 2}$ times after intravitreal injection of triamcinolone acetonide in vitrectomized eyes in both animal models and human eyes [34, 35].

Our search of the literature failed to reveal any publications on the pharmacokinetics of bevacizumab in vitrectomized human eyes. This is a novel finding, which may have significant clinical implications. Bevacizumab is frequently injected into previously vitrectomized eyes in clinical practice, and its increased clearance may mandate more frequent injections. This concept is supported by an earlier study that reported a reduced effect of bevacizumab injections in vitrectomized eyes [36].

Several limitations of this study warrant consideration. First, topical bevacizumab was administered for only 12 days, and it is possible that a regimen of more frequent applications for a longer period of time might have resulted in detectable intraocular bevacizumab levels. This is probably unlikely, since the corneal epithelium was intact in all of our studied eyes. Second, since no patients with corneal NV were included, it is not possible to predict the pharmacokinetics of topical bevacizumab in eyes with that pathology. Third, we acknowledge that the number of patients who received intravitreal bevacizumab was small, although there is a precedent to describe as few as two patients in pharmacokinetic studies in human eyes [25-28]. Fourth, we note that the presence of vitreal hemorrhage in eyes that received intravitreal bevacizumab injections may have altered 
its pharmacokinetics. However, this has not been established in any study, and since all eyes treated intravitreally had VH, we contend that comparing them is methodologically sound. Finally, fixed volumes were assumed when calculating bevacizumab amounts from vitreal and serum samples. Although estimating individual vitreal and serum volumes from individual patient's axial length and weight might have allowed more accurate calculations, their effect on $T_{1 / 2}$ calculation would have been very small and clinically insignificant.

In conclusion, our results indicate that topical bevacizumab does not penetrate into the aqueous or vitreous following short-term use. Our intention was to perform pharmacokinetic calculations, but intraocular bevacizumab was not detected following topical administration. These results are consistent with previous studies, and support the growing body of evidence attesting to efficient and safe topical use of bevacizumab. Further studies of the pharmacokinetics in patients with corneal NV are warranted. Additionally, our results on vitreal and systemic $T_{1 / 2}$ following intravitreal bevacizumab injection corroborate previous studies. Finally, our study demonstrates for the first time that the $T_{1 / 2}$ of intravitreal bevacizumab in a previously vitrectomized eye is significantly reduced. More comprehensive studies of bevacizumab pharmacokinetics in previously vitrectomized eyes are warranted, and may lead to the formation of different treatment regimens for such patients.

Conflict of interest No author has any proprietary interest in the publication of this report.

Source of support Ministry of Health, Office of the Chief Scientist, Israel. Grant 3-00000-4647 and the Lirot Association.

Open Access This article is distributed under the terms of the Creative Commons Attribution License which permits any use, distribution, and reproduction in any medium, provided the original author(s) and the source are credited.

\section{References}

1. Lim LS, Mitchell P, Seddon JM, Holz FG, Wong TY (2012) Agerelated macular degeneration. Lancet 379(9827):1728-1738

2. Brechner RJ, Rosenfeld PJ, Babish JD, Caplan S (2011) Pharmacotherapy for neovascular age-related macular degeneration: an analysis of the $100 \% 2008$ medicare fee-for-service part B claims file. Am J Ophthalmol 151:887-895

3. Stewart MW (2012) The expanding role of vascular endothelial growth factor inhibitors in ophthalmology. Mayo Clin Proc 87:77-88

4. Manzano RPA, Peyman GA, Khan P, Carvounis PE, Kivilcim M, Ren M, Lake JC, Chévez-Barrios P (2007) Inhibition of experimental corneal neovascularization by bevacizumab (Avastin). Br J Ophthalmol 91:804-807

5. Spaide RF, Laud K, Fine HF, Klancnik JM Jr, Meyerle CB, Yannuzzi LA, Sorenson J, Slakter J, Fisher YL, Cooney MJ (2006) Intravitreal bevacizumab treatment of choroidal neovascularization secondary to age-related macular degeneration. Retina 26:383-390

6. Bock F, Onderka J, Dietrich T, Bachmann B, Kruse FE, Paschke M, Zahn G, Cursiefen C (2007) Bevacizumab as a potent inhibitor of inflammatory corneal angiogenesis and lymphangiogenesis. Invest Ophthalmol Vis Sci 48:2545-2552

7. Kim SW, Ha BJ, Kim EK, Tchah H, Kim TI (2008) The effect of topical bevacizumab on corneal neovascularization. Ophthalmology $115: 33-38$

8. Uy HS, Chan PS, Ang RE (2008) Topical bevacizumab and ocular surface neovascularization in patients with Stevens-Johnson syndrome. Cornea 27:70-73

9. Dastjerdi MH, Al-Arfaj KM, Nallasamy N, Hamrah P, Jurkunas UV, Pineda R, Pavan-Langston D, Dana R (2009) Topical bevacizumab in the treatment of corneal neovascularization. Arch Ophthalmol 27: 381-389

10. DeStafeno JJ, Kim T (2007) Topical bevacizumab therapy for corneal neovascularization. Arch Ophthalmol 125:834-836

11. Nomoto H, Shiraga F, Kuno N, Kimura E, Fujii S, Shinomiya K, Nugent AK, Hirooka K, Baba T (2009) Pharmacokinetics of bevacizumab after topical, subconjunctival, and intravitreal administration in rabbits. Invest Ophthalmol Vis Sci 50:4807-4813

12. Yoeruek E, Ziemssen F, Henke-Fahle S, Tatar O, Tura A, Grisanti S, Bartz-Schmidt KU, Szurman P, Tübingen Bevacizumab Study Group (2008) Safety, penetration and efficacy of topically applied bevacizumab: evaluation of eyedrops in corneal neovascularization after chemical burn. Arch Ophthalmol 86:322-8

13. Dastjerdi MH, Sadrai Z, Saban DR, Zhang Q, Dana R (2001) Corneal penetration of topical and subconjunctival bevacizumab. Invest Ophthalmol Vis Sci 52:8718-8723

14. Kim MJ, Han ES, Kim JW, Kim TW (2010) Aqueous humor concentration of bevacizumab after subconjunctival injection in rabbit. J Ocul Pharmacol Ther 26:49-53

15. Meyer CH, Krohne TU, Holz FG (2012) Concentrations of unbound bevacizumab in the aqueous of untreated fellow eyes after a single intravitreal injection in humans. Acta Ophthalmol 90:68-70

16. Xu HM, Zhou YX, Shi MG (2008) Exploration of three-dimensional biometric measurement of emmetropic adult eye-ball by using magnetic resonance imaging technology. Zhonghua Yan Ke Za Zhi 44:1007-1010

17. Prausnitz MR, Noonan JS (1998) Permeability of cornea, sclera, and conjunctiva: a literature analysis for drug delivery to the eye. J Pharm Sci 87:1479-1488

18. Brereton HM, Taylor SD, Farrall A, Hocking D, Thiel MA, Tea M, Coster DJ, Williams KA (2005) Influence of format on in vitro penetration of antibody fragments through porcine cornea. Br J Ophthalmol 89:1205-1209

19. Galor A, Yoo SH (2010) Corneal melt while using topical bevacizumab eye drops. Ophthalmic Surg Lasers Imaging 9:1-3

20. Kim TI, Chung JL, Hong JP, Min K, Seo KY, Kim EK (2009) Bevacizumab application delays epithelial healing in rabbit cornea. Invest Ophthalmol Vis Sci 50:4653-4659

21. Gaudreault J, Fei D, Ruzit J, Suboc P, Shiu V (2005) Preclinical pharmacokinetics of ranibizumab after a single intravitreal administration. Invest Ophthalmol Vis Sci 46:726-733

22. Koenig Y, Bock F, Horn F, Kruse F, Straub K, Cursiefen C (2009) Short- and long-term safety profile and efficacy of topical bevacizumab (Avastin) eye drops against corneal neovascularization. Graefes Arch Clin Exp Ophthalmol 247:1375-1382

23. Bock F, Onderka J, Rummelt C, Dietrich T, Bachmann B, Kruse FE, Schlötzer-Schrehardt U, Cursiefen C (2009) Safety profile of topical VEGF neutralization at the cornea. Invest Ophthalmol Vis Sci 50: 2095-2102

24. Wang Y, Fei D, Vanderlaan M, Song A (2004) Biological activity of bevacizumab, a humanized anti-VEGF antibody in vitro. Angiogenesis 7:335-345 
25. Beer PM, Wong SJ, Hammad AM, Falk NS, O’Malley MR, Khan S (2006) Vitreous levels of unbound bevacizumab and unbound vascular endothelial growth factor in two patients. Retina 26:871-876

26. Zhu Q, Ziemssen F, Henke-Fahle S, Tatar O, Szurman P, Aisenbrey S, Schneiderhan-Marra N, Xu X, Grisanti S, Tübingen Bevacizumab Study Group (2008) Vitreous levels of bevacizumab and vascular endothelial growth factor-a in patients with choroidal neovascularization. Ophthalmology 115:1750-1755

27. Meyer CH, Krohne TU, Holz FG (2011) Intraocular pharmacokinetics after a single intravitreal injection of $1.5 \mathrm{mg}$ versus $3.0 \mathrm{mg}$ of bevacizumab in humans. Retina 31:1877-1884

28. Christofordis JB, Carlton MM, Knopp MV, Hinkle GH (2011) PET/ CT imaging of I-124-radiolabeled bevacizumab and ranibizumab after intravitreal injection in a rabbit model. Invest Ophthalmol Vis Sci 52:5899-5903

29. Bakri SJ, Snyder MR, Reid JM, Pulido JS, Singh RJ (2007) Pharmacokinetics of intravitreal bevacizumab (Avastin). Ophthalmology 114:855-859

30. Sinapis CI, Routsias JG, Sinapis AI, Sinapis DI, Agrogiannis GD, Pantopoulou A, Theocharis SE, Baltatzis S, Patsouris E, Perrea D
(2011) Pharmacokinetics of intravitreal bevacizumab (Avastin) in rabbits. Clin Ophthalmol 5:697-704

31. Kim H, Fariss RN, Zhang C, Robinson SB, Thill M, Csaky KG (2008) Mapping of the neonatal $\mathrm{Fc}$ receptor in the rodent eye. Invest Ophthalmol Vis Sci 49:2025-2029

32. Kim H, Robinson SB, Csaky KG (2009) FcRn receptor-mediated pharmacokinetics of therapeutic IgG in the eye. Mol Vis 15:28032812

33. Roopenian DC, Akilesh S (2007) FcRn: the neonatal Fc receptor comes of age. Nat Rev Immunol 7: 715-725

34. Chin HS, Park TS, Moon YS, Oh JH (2005) Difference in clearance of intravitreal triamcinolone acetonide between vitrectomized and nonvitrectomized eyes. Retina 25:556-560

35. Beer PM, Bakri SJ, Singh RJ, Liu W, Peters GB, Miller M (2003) Intraocular concentration and pharmacokinetics of triamcinolone acetonide after a single intravitreal injection. Ophthalmology 110 : 681-686

36. Yanyali A, Aytug B, Horozoglu F, Nohutcu AF (2007) Bevacizumab (Avastin) for diabetic macular edema in previously vitrectomized eyes. Am J Ophthalmol 144:124-126 